\title{
MODELLING IN SCIENCE AND EDUCATION: THE WAY TO GET THE BETTER RESULTS IN REAL THROUGH THE USE OF AN IDEALIZED UNDERSTANDING
}

\author{
Todar Lakhvich \\ Belarusian State Medical University, Republic of Belarus
}

The initial period of Science was almost completely empirical. Both Science itself and Science Education were based on the experiment. Then Science gained the new paradigm which was rather formal by nature and fundamental in methodological meaning. Still the tool for interconversion between the empiric and theoretical moieties seems to be the core point of the consideration and can be associated with the problem of modeling, which is one of the most important in modern Science. Earlier we postulated (Lakhvich, Kostareva, Lehankova, 2009; Lakhvich, 2010) that adequate modelling and visualization in particular is to be the core element for the modern Educational model and paradigm for Science. A great number of publications, devoting to the problem, confirm dramatically its relevance. Still the discussion in many aspects manifested the initial stage of the recognition, models mostly being discussed in terms of object recognition and computational modeling. We consider the category of modelling is more comprehensive and can be discussed in various aspects, some of them are all-pervading philosophy principle (Harnad, 1987), psychological tool for cognition (Lakhvich, Kostareva, Lehankova, 2009) and finally the model having for Science its own complex structure.

Models are widely used in all scientific disciplines. It's worthy to note they are appropriate not only for theoretical considerations but useful in the framework of more practically oriented fields of Science. The typology of models has been developed regarding their hierarchy in dependence of their relative similarity (Trindle, 1984; Tomasi, 1986).

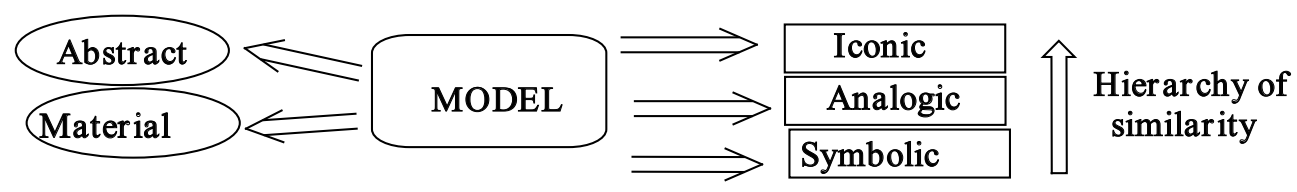

Figure 1: Typology of models.

Still it has been found (Tomasi, 1999) that for theoretical investigation the models can be classified in another way. The components of this subsystem are hierarchically dependent and the most comprehensive definition refers to interpretative model. The latter collects all the aspects of study which are used for interpretation of the application of the mathematical model to the material model, according to the limits and condition the physical model superimposes. The interpretative model is absolutely appropriate for speculation of different scientific concepts; the adequacy of such a model ought to be judged with the aid of criteria. 


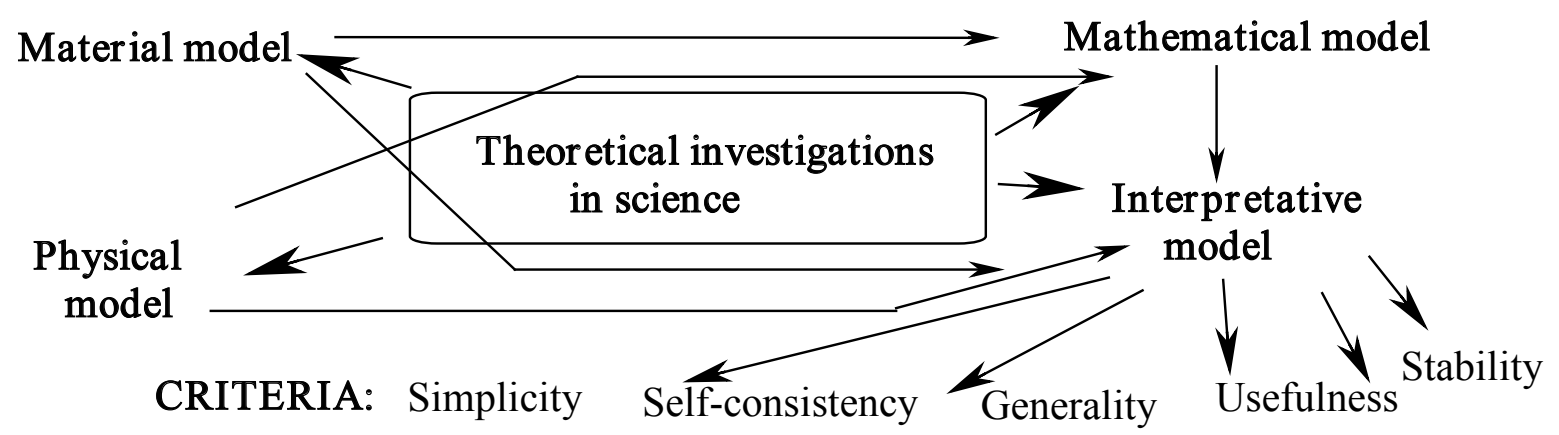

Figure 2: The application of the interpretative model and its assessment by criteria.

Earlier we postulated (Lakhvich, Kostareva, Lehankova, 2009) a few additional criteria to judge models in a didactic framework. Models for the academic disciplines need to be adequate, effective, contemporary, exciting, and finally appropriate for successive usage (taking in account the need for continuity of education). The similarity between real objects and models can almost be neglected in this context. To create an effective molecular model, we need to accept the influence of many features and conditions, which include both the nature of real objects and didactical (for the academic disciplines) aspects.

Molecular docking is a method of molecular modeling. It predicts the preferred orientation of one molecule relative to another at their bonding to form a stable complex. Knowledge of the preferred orientation allows to forecast the strength of the association, or affinity to binding between two molecules. This modelling is widely used in Molecular Biology, Computational Chemistry and Drug Design (Scientific paradigm) and can be effectively introduced in Educational process (Educational paradigm).

Molecular docking has been developed actively for about three decades (Lengauer, Rarey, 1996; Kitchen, Decornez, Furr, Bajorath, 2004). But for the first time I faced colleagues doing it in the fall of 2013 when I did my plenary report in Conference on Organic Chemistry. My report was devoted to chemical experiment and it was in the line with the majority of other reports. We, organic chemists are a bit snobbish and conceited about our involvement in the process of synthesis in chemical laboratory. And reports about molecular docking were discussed in terms of inability to do something in "real chemistry". But a few years later working with Pharmacy students I remembered about "docking reports" and decided to simulate in silico the activity of potential TB drugs. It was done mostly because of the cheap equipment we needed for student research and inspired by the work of the colleague who studied some biochemical issues with the aid of molecular docking. Initially I was very skeptical about the value of the experiment. For sure we used species synthesized and tested on TB activity previously. My editorial is not the place for description of the experiment. But I must say my attitude to the technique has changed dramatically. When organized properly, docking modelling gives really new knowledge. But only in the case we use the proper scientific approach. Based on the experiment we elaborated the model of interaction (we needed to propose the protein fragment for simulation in silico). Then we compare the results of in silico computations and tests ex vitro (on TB strands) and then generated mentally the new structures with fragments of definite shape and orientation to bond more effectively with receptor. Just a normal scientific research based on proper scientific paradigm!

Moreover, as an acting professor I found that modelling was attractive and interesting for students. They really were involved both in experiment (it was available and productive) and in the process of acquisition of knowledge. They found out a lot about the subject of their professional interest and shared their knowledge with mates.

Sometimes we hear from our colleagues working in the field of Science and Science Education about the uselessness of models and simulations. They propose only to train skills to teach some operations which will be used in future professionally. I dare say it's a college approach to prepare blue-collar workers for a primitive industry.

There are two main different ways of reasoning (Harnad, 1987). For most people it's natural to do their reasoning on the semantic level. Graphic tools have always played an important role in this reasoning style. When using a formal and abstract language and exact rules governing the creation and transformation of statements in this language, one reveals the ability to work on the syntactic level. And this can be postulated as quite a different way of reasoning, which is based almost exclusively by logicians. The use of graphic forms in this case is also possible, though it requires more time and technological complexity. For exact sciences, primarily mathematics based stud- 
ies, the use of computers can raise the efficiency of the method. Still for Science even before the informational revolution the special tools of interconversion between empirical knowledge and different types of reasoning had been developed, the latter originates from the very core of Science knowledge.

Science Education is based on models which help to present the previous knowledge and to develop the new one. Science is integrative force and Science Education can help to understand the changing world. Science Education does so and there are many examples strengthening the point. It is one more and may be the most exciting issue demonstrating the unity of knowledge and necessity for cooperation. The latter can help to develop the core model for more effective Education based on all traditions and contemporary trends.

We do believe our authors will develop and create new models, in particular those which can be applied in the educational process. And these models for the academic disciplines need to be adequate, effective, contemporary, exciting, and finally appropriate for successive usage. They must be attractive and understandable, and not only for readers and editors but also for students, and the last regarding in the first place. And never be afraid of idealized concepts.

\section{References}

Harnad, S. (1987) Category induction and representation. In: Categorical Perception: The Groundwork of Cognition. New York: Cambridge UniPress.

Kitchen, D. B., Decornez, H., Furr, J. R., Bajorath, J. (2004). Docking and scoring in virtual screening for drug discovery: Methods and applications. Nature Reviews Drug Discovery, 3 (11), 935-949. doi: 10.1038/nrd1549.

Lakhvich, T., Kostareva, A., Lehankova, V. (2009). Visualisation-assisted chemistry teaching of hearing-impaired students. In: M. Bilek Ed.), Research, theory and practice in chemistry didactics. Hradec Kralove: Gaudeamus, 221-222.

Lakhvich, T. (2010). Beautylity of chemistry visualization: Whether useful can be aesthetic. Problems of Education in the 21st Century, 19, 46-50.

Lengauer, T., Rarey, M. (1996). Computational methods for biomolecular docking. Current Opinion in Structural Biology, 6 (3), 402-406.

Trindle, C. (1984). The hierarchy of models in chemistry. Croatia Chemica Acta, 57 (6), 1231-1245.

Tomasi, J. (1988). Models and modelling in theoretical chemistry. Journal of Theoretical Chemistry, 179, 273-292.

Tomasi, J. (1999). Towards "Chemical Congruance" of the models in theoretical chemistry. HYLE - An International Journal for the Philosophy of Chemistry, 5 (2), 79-115. 